\title{
أثر العناصر الطبيعية والهندسية على القيم التشكيلية والتعبيرية في المنحوتات الجدارية المعاصرة
}

\author{
إعلاد

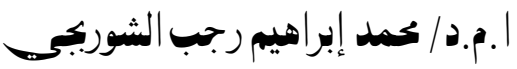 \\ أستاذ النحت المسـاعد بقسم التربية الفنية \\ كلية التربية النوعية ـ جامعة المنصورة \\ أ / أمنية صبركى حامد احمد صيام \\ طالبة ماجستير بقسم التربية الفنية \\ كلية التربية النوعية ـ جامعة المنصورة \\ | ا.م.د/ سلالمه محمد علحس \\ أستاذ النحت المسـاعد بقسم التربية الفنية

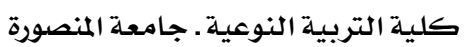 \\ م/إبراهيم أحمد السيد \\ مدرس النحت بقسم التربية الفنية \\ كلية التربية النوعية ـ جامعة المنصورة
}

مجلة بحوث التربية النوعية ـ جامعة المنصورة

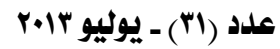




\title{
أثر العناصر الطبيهية والهندسيية على القيم التشكيلية والتعبيرية في المهوتات البمدارية المعاصرة
}

\author{
إعداد

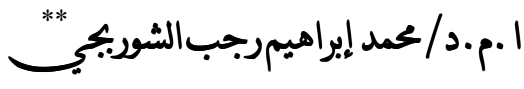 \\ أ/أمنيةصبركحامد احمد صيام
}

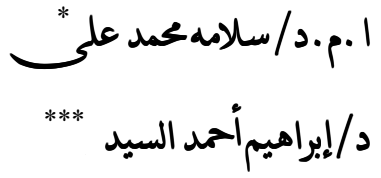

هلخص البحث:

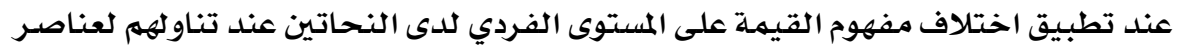

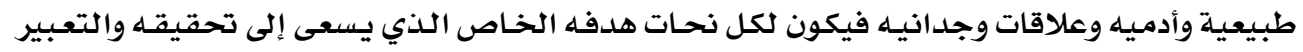

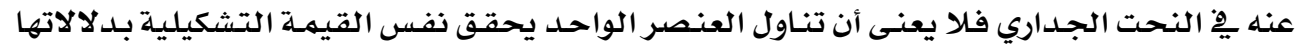

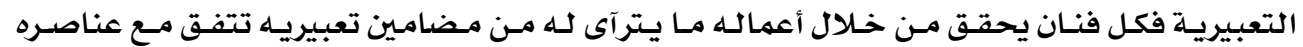
وموضوعه الفني وفكره الابداعى.

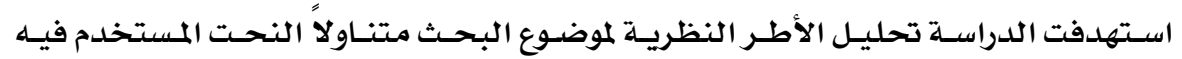

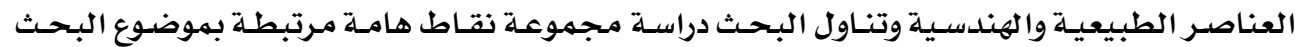

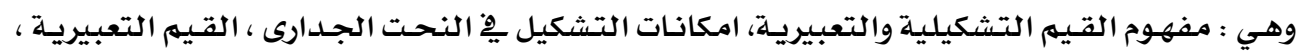

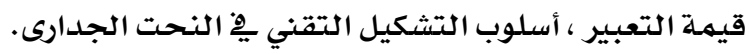

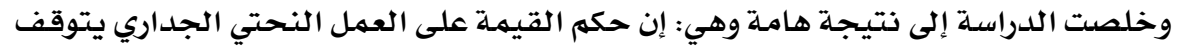

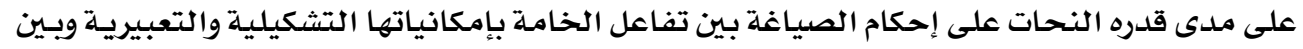

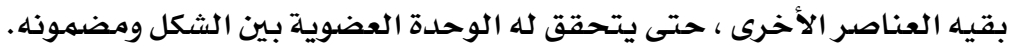

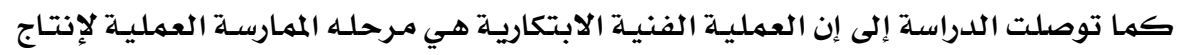

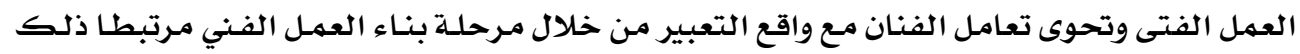
بعلاقات الشكل والمضمون واتجوى دعامل الرمزينان مالموضوع. 


\title{
أثر العناصر الطبيعية والهندسية على القيه التشكيلية والتعبيرية في المنحوتات الجدارية المعاصرة
}

\author{
إعداد

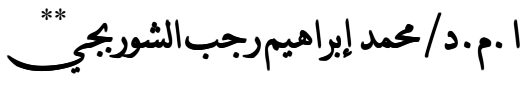 \\ أ أمنيةصبركحامد احمد صيام

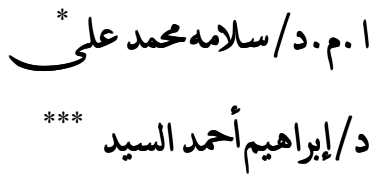

همبدة

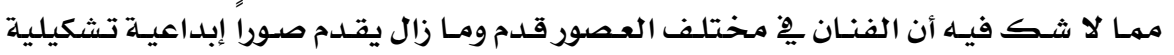

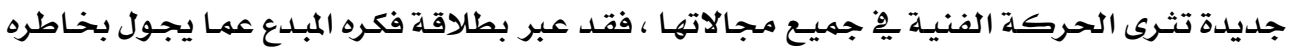

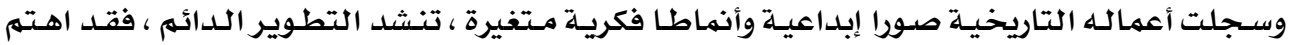

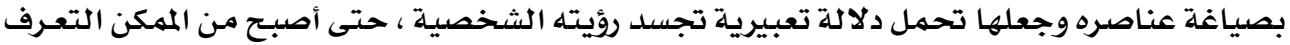

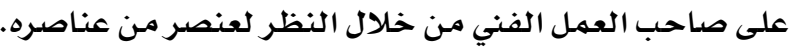
المصري القديم أخذ أغلب مفرداته التشكيلية مـن العناصـر العضوية والهندسية فكونت لها

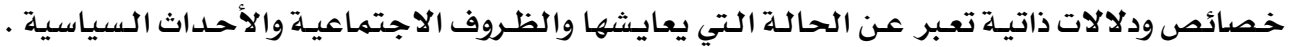

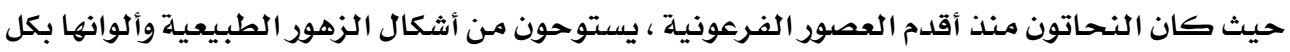

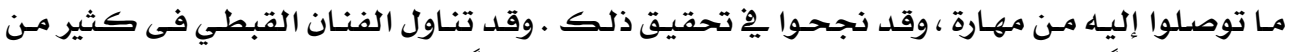

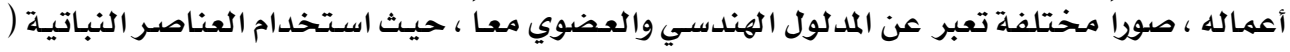

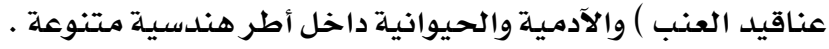

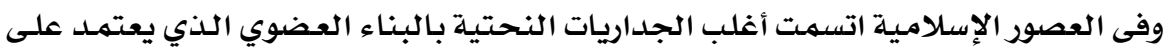

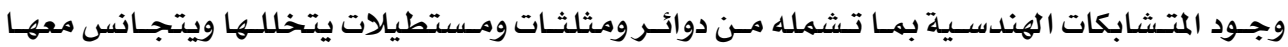

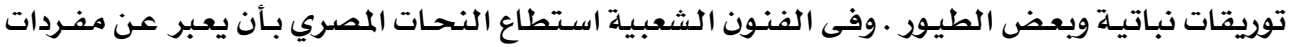

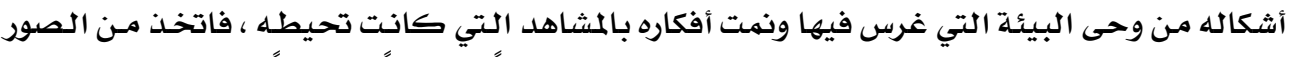

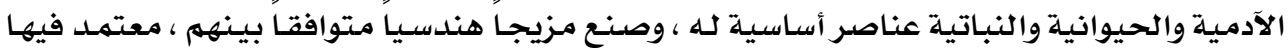
على التبسيط والتلخيص الخطى لمفرداته التشكيلية. 


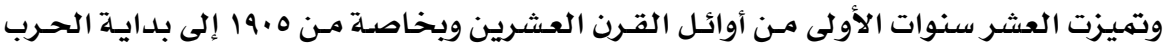

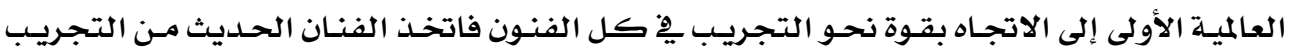

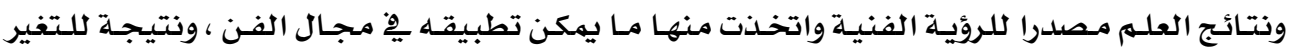

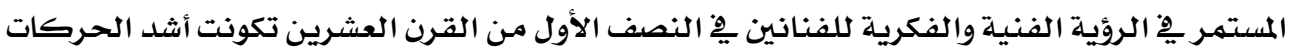

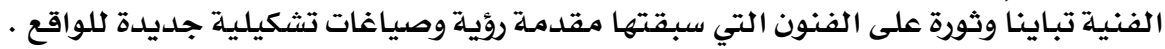
ومن خلال العرض السابق يمكن تحديد مشكلة البحث الحالي ِِّ التساؤلات التالية:

• ما إمكانية توظيف واستلهام مفردات اللغة الفنية لأعمال رواد من النحت الجداري؟

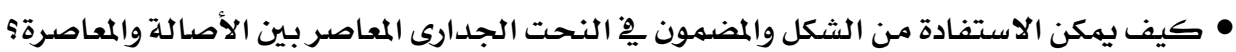

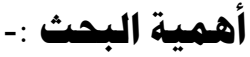

يقصد بالأهمية الفئات المستفيدة من نتائج هذه الدراسـة

$$
\text { تتجهه أهمية البحث إلى : }
$$

ا- تقديم مداخل ابتكاريه جديدة يِّ صياغة العناصر العضوية وا لهندسية بأسلوب معاصر يثري

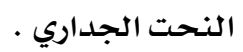

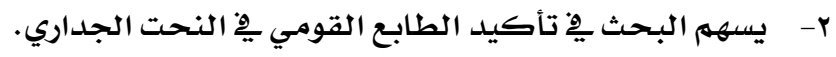

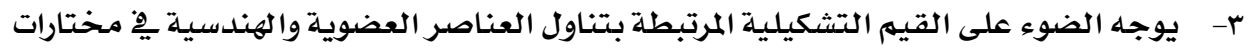
من أعمال الفنانين المصريين المعاصرين.

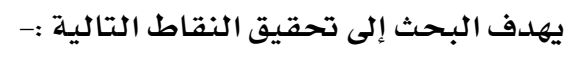

ا- الإفـادة مـن بعض أعمـال الفنـانين المصريين المعاصـرين لتعميق الوعي بأهميـة التفاعل بـين

$$
\text { الطبيعة والنحت الجداري. }
$$

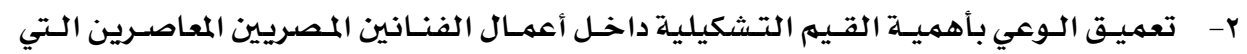

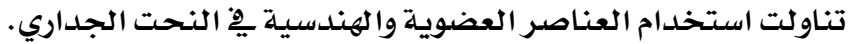

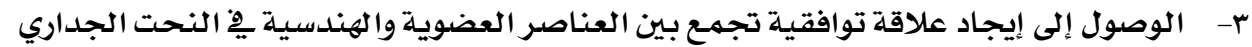

\section{فروض البحث :-}

ا- لا توجد إمكانية لاستيعاب النحت الجداري للمتغيرات البنائية الفنيـة لأعمال عينـة مختـارة

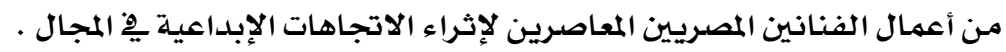

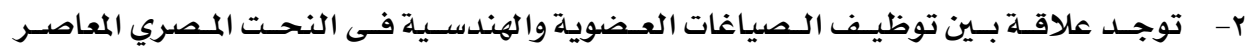

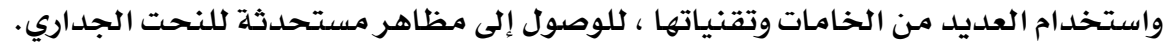

يعتمد البحث على المنهج الوصفي باعتباره أنسب المناهج لدراسة الإطار النظري للبحث . 
Expressive and plastic's value's: أولا: مفهوم القيم التشكيلية والتعبيرية

حينهـا نستعرض بعض المفـاهيه التى توضـح مفهوم كـلا مـن القيهم التشكيلية والتعبيريـة

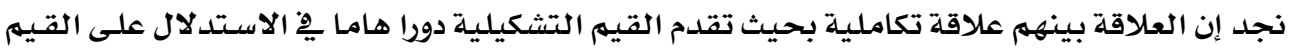

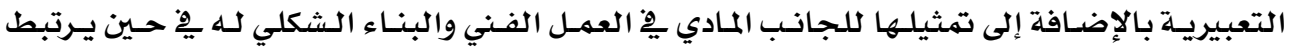

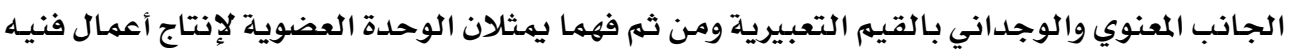

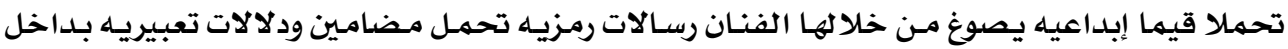
العمل الفني وتتوقف درجه الاستمتاع بتلك الرسالة واستيعابها على ما لدى المتلقي مـن خبره وووعى مئى فني

ويوضـح (محمــد اسـحق قطـب) القـيهم التشكيلية والتعبيريـة على أنهـا : " هـي العلاقـات

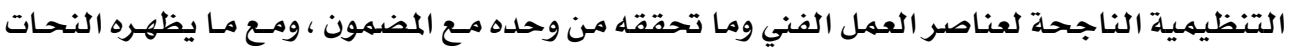

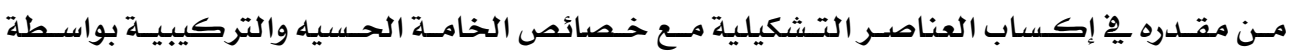

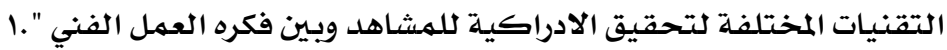

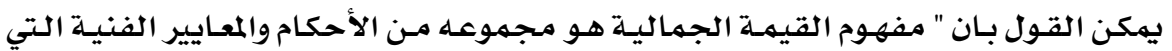

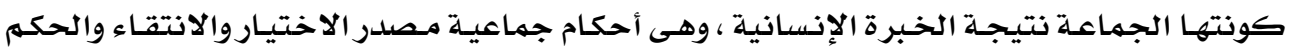

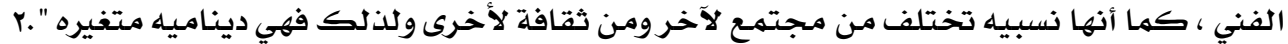

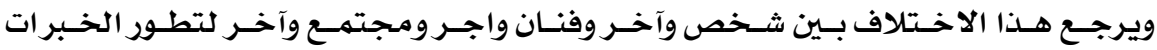

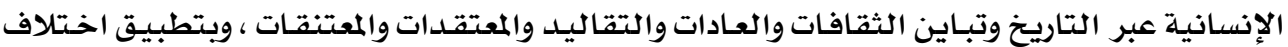

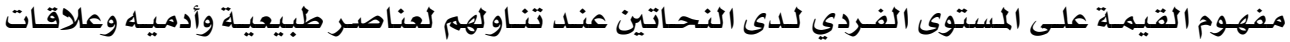

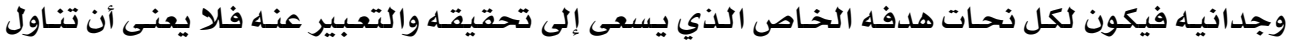

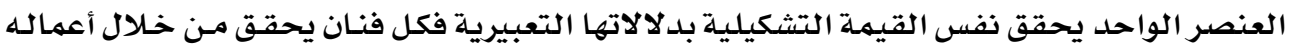

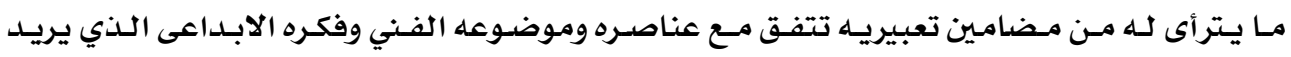

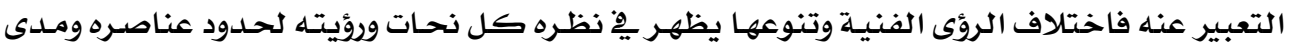

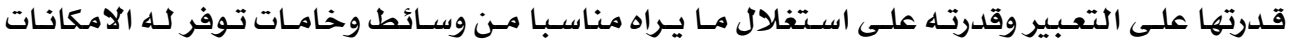

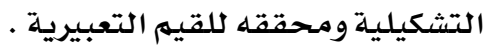
إن العملية الفنية الابتكارية هي مرحلـه الممارسـة العملية لإنتاج العمل الفنى وتحوى تعامـل

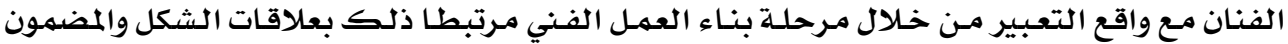

محمد اسحق قطب : المفهوم الحمالي لتناول الخامة فِ النحت الحديث - رسالة دكتوراه غير منشورة - - كلية التربية

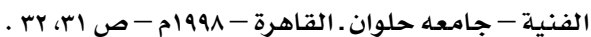

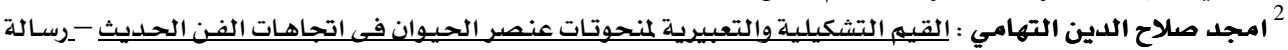

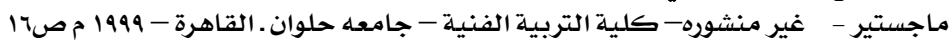




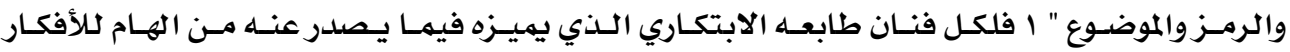

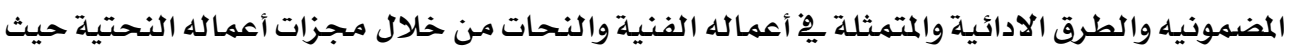

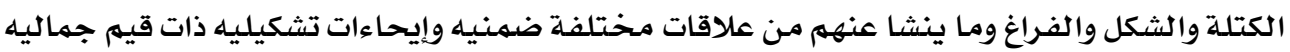

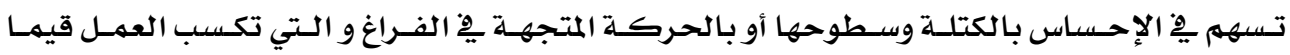
تعبيريـه.

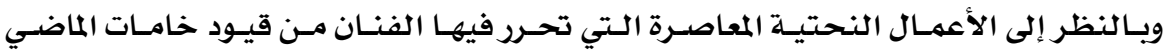

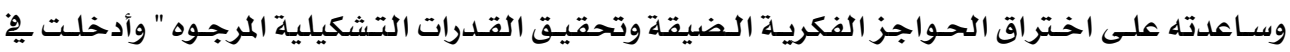

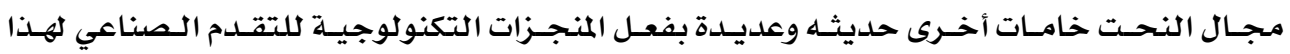
القرن"r.

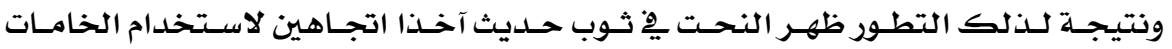

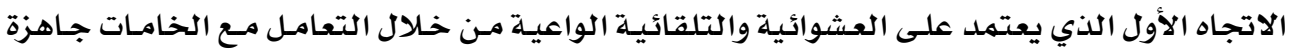

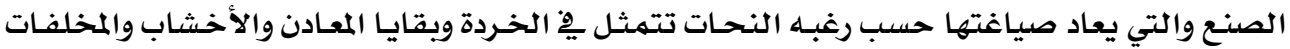

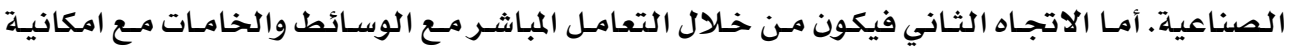

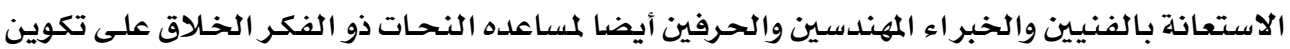
ملامـح فكرته الإبداعية وانطلاقها إلى حيز الوجود محمله بالمضامـين الفنية والقين القيهم التشكيلية. ثانياً: امكانات التشكيل في النحت الجدانداريل ـ إلخامة : Material

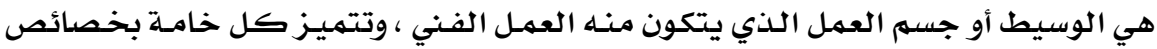

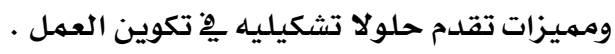

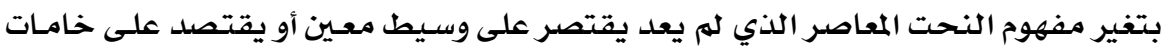

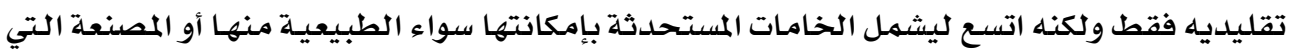

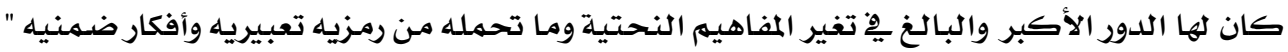

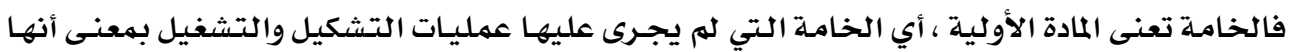

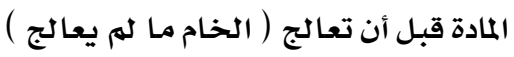
فبدون الخامـة يِّ العمل الفني لا يكون هنـاك شكلا يمكن إدراكـه والحكهم عليـه ،لأنها تؤثر

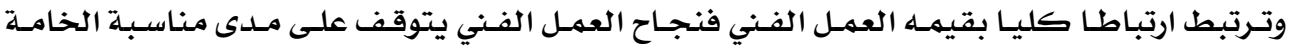

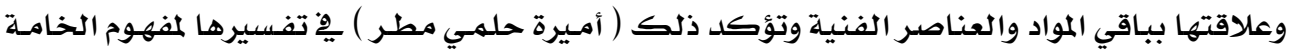

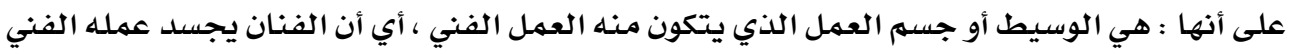

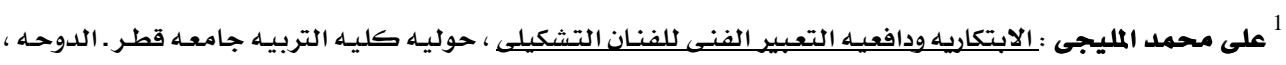

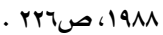

2 -Robert Myron, Abner sundell: Modern Art in American" , Cromwell collier , N.Y1971- P162. 


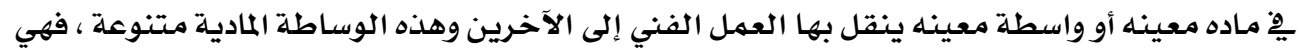

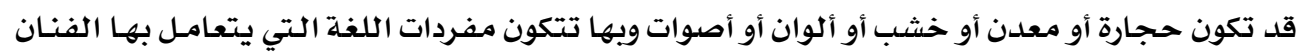

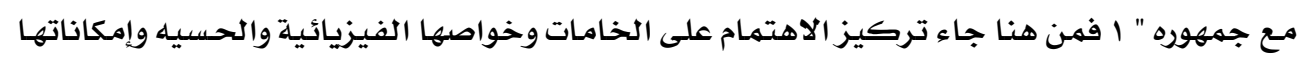

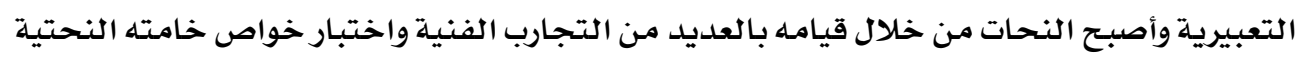

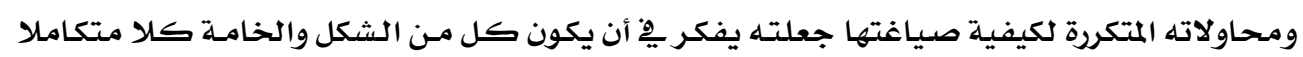

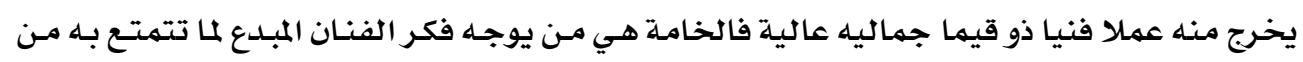

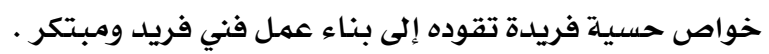
ثالثا: القيم التعبيرية Expressive Value

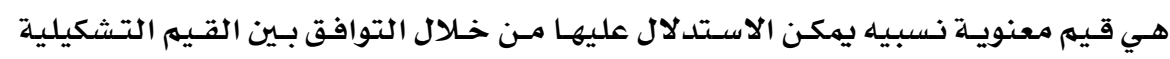

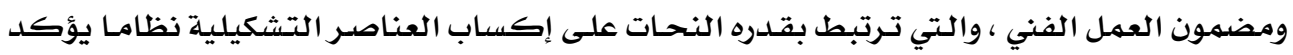

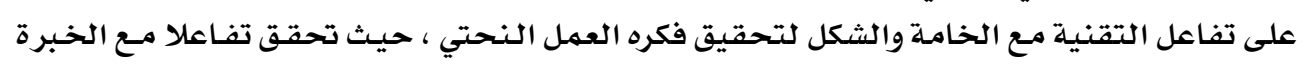

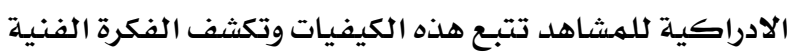

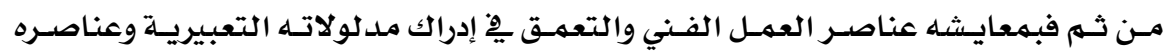

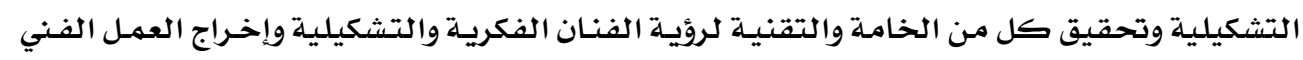

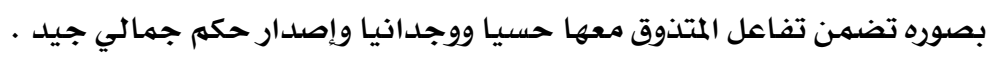
رابعا: قيمة ( التعبير ): Expressive

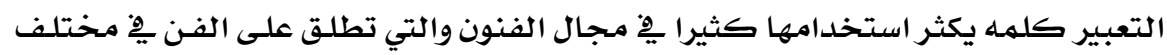

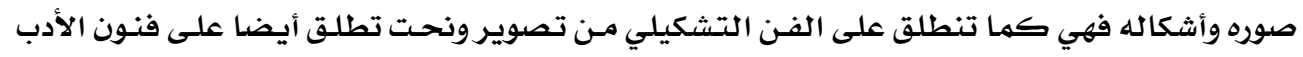

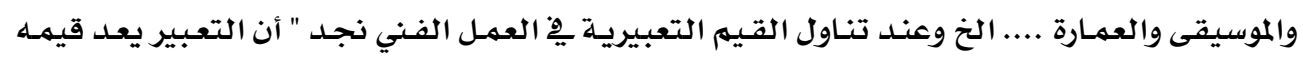

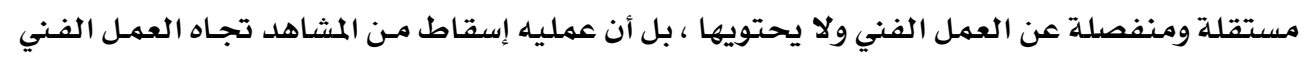

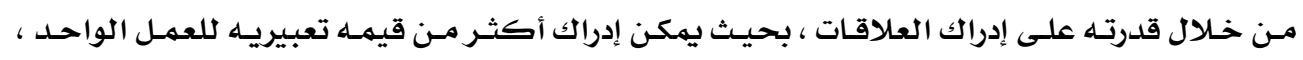

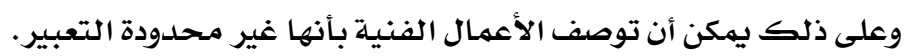

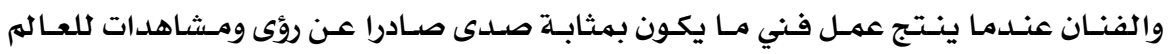

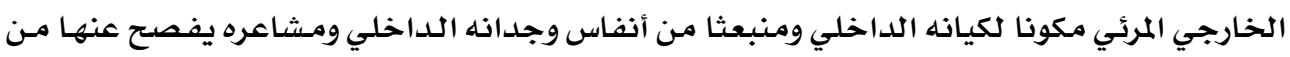

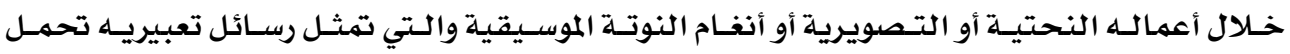

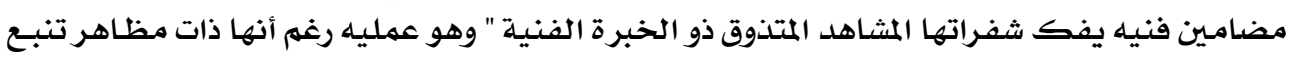

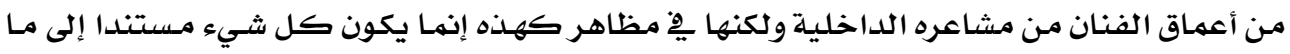

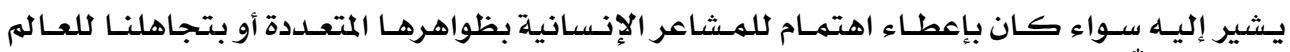

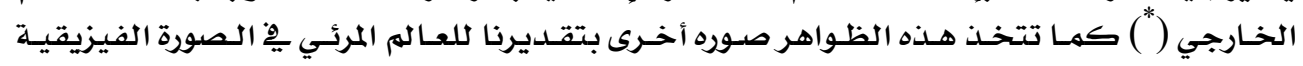

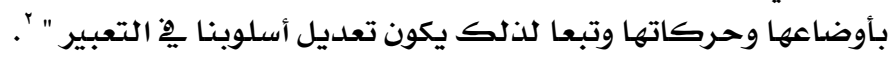

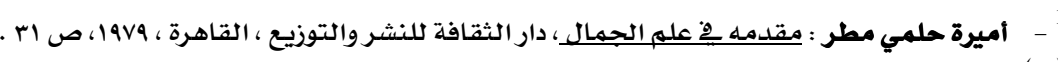

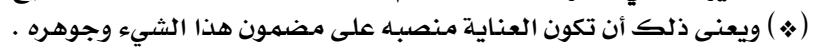

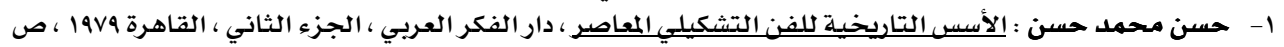


بحيث يعد التعبير شيء معنوي شعوري غير مادي يدركه المتلقي ( المتلذوق للفن ) من خـالال

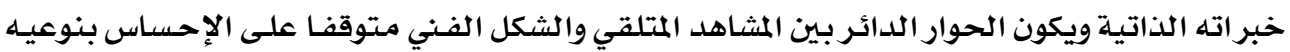

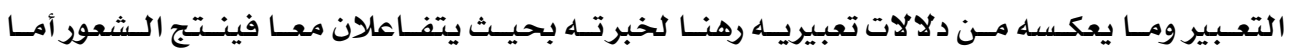

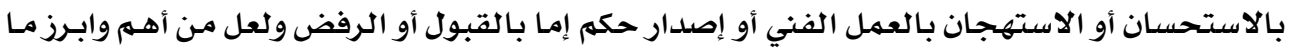

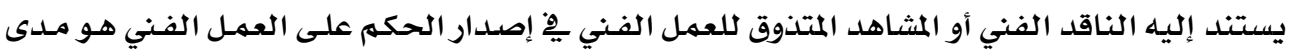

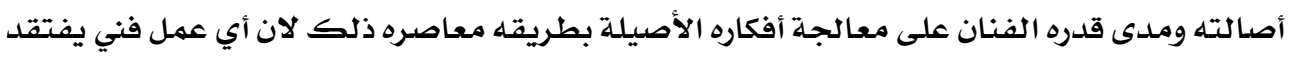

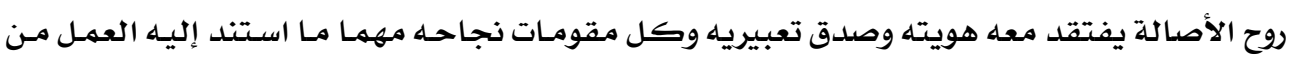

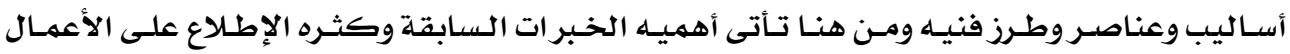

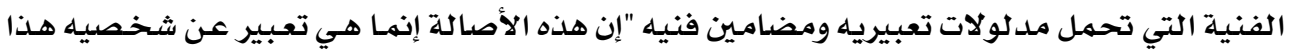

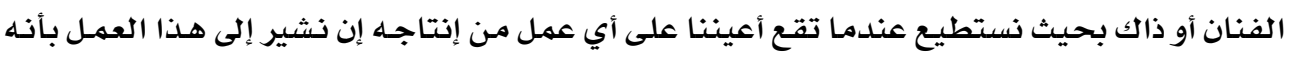

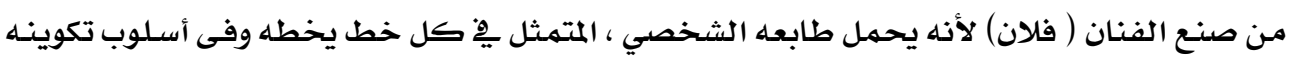

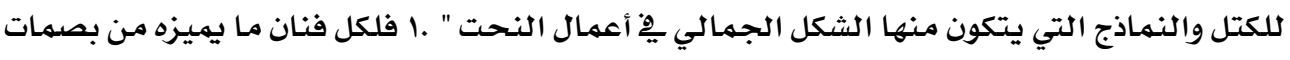

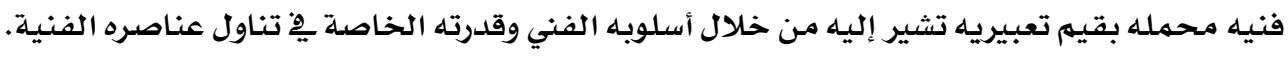

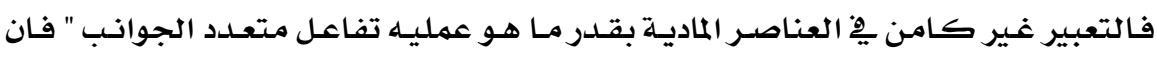

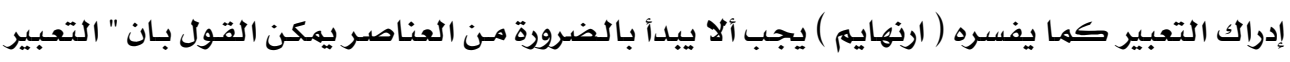

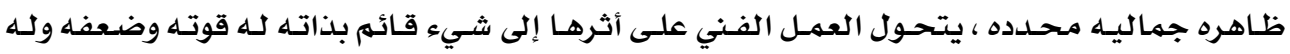

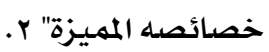

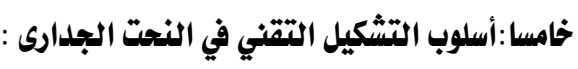

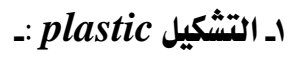

" التشكيل هو طريقه بناء العمل الفني بواسطة خامـة من الخامـات من خلال تفاعل الفنـان

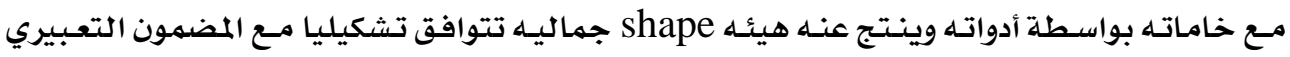

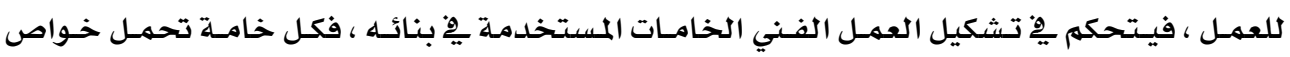

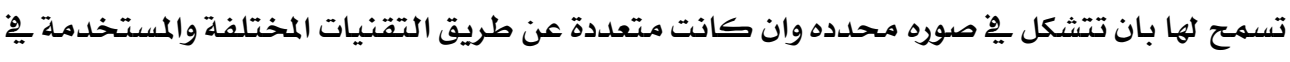

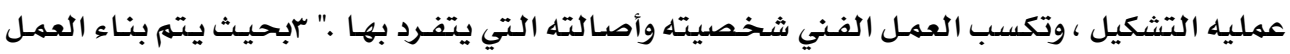

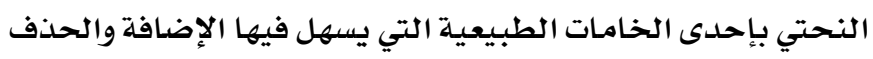
r ـ ارتباط القيم التعبيرية بالتقنية : باحسي الخات الطبيعة التئي نجد أن ما يعبر عنه المظهر الشكلي للعمل النحتي الذي يشتهل على الشكل والملمس واللـون

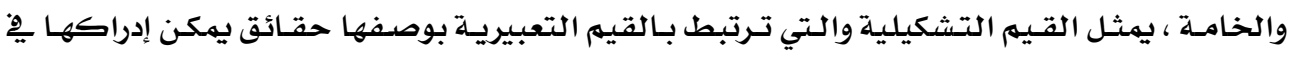
العمل الفني. 


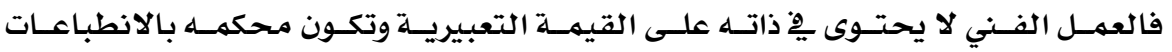
وإسقاطات كل شخص على حده والتي تتبـاين وتختلف يِّ إصدار حكم قيهي وتعبيري يِّا العمل الفني

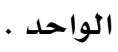

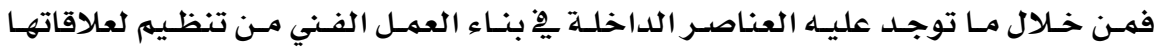

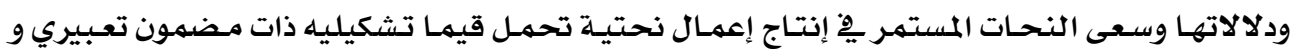
تتصف بالجمال " فالتعبير كقيمه للعمل الفني يسقطه كل شخص من عنده ، ولهذا فيان جانبـا مـن هذه القدرة والقيمـة تخص الإنسـان المدرك ، وتعتمد على خبرته الذاتيـة التي تؤثر ِِ رؤيته الإدراكيـة. والجانب الآخر يخص الشكل الذي تفصـح هيئتـه ونظامـه عن مـا يحتويـه بصوره بليغـة بحيـث تصبـح

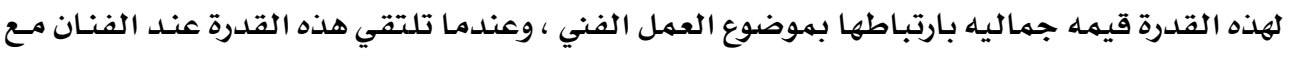

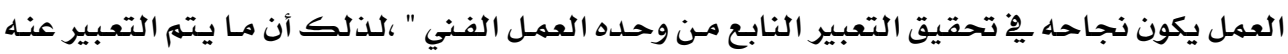
من خلال العمل الفني يرجح إلى الفنان وقدرته يخ إحكام التتظيم الشكلي للخامـة والموضوع . فكان عليه دوما اكتسـاب الخامة لشكلها عن طريق التقنية الحديثة بهدف أحداث تغيير فِ شكل المادة الخـام وإكسـابها نظامـا محدد المعالم ومحقق للهـدف الفـني المطلـوب ويظهـر ذلك واضـحا

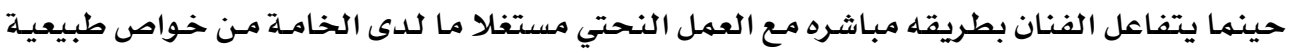

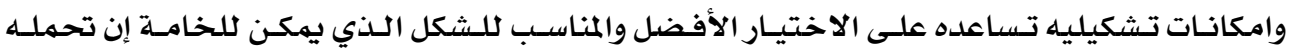
وتحقيـق غايـاتـه الفنيـة ودلالاتهـ التعبيريــة لان دور الخامسة والـشكل والتعـبير متـوازي يْ طريـق إظهـار

$$
\text { قيمها العمل الفني ونجاحهـ . }
$$

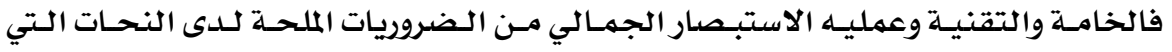

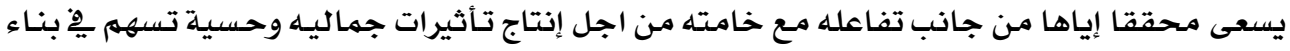
وتكوين عملـه الفني ومـن هنـا أصبـحت الخامسة والتقنيـة مـن أهـم مـا يهيـز النـحت المعاصـر وومـن ابـرز مـا

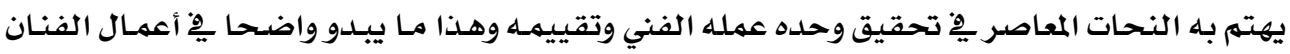

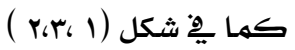

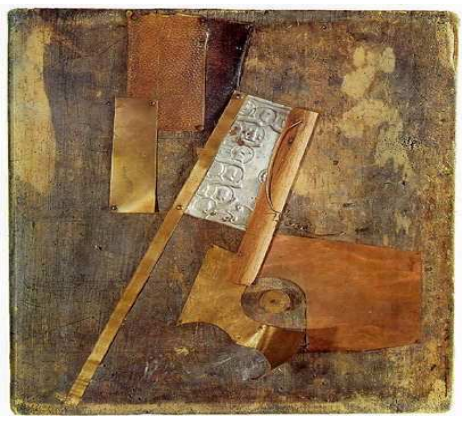

شكل (1)

الخشب والورق المقوى وبعض شرائح المعدن

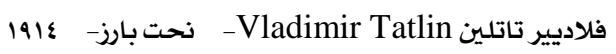


$$
\text { مجلة بحوث التربية النوعية - علد اس - يوليو ما•r r ب }
$$

شكل (2 ) الخشب والابلكاش والكرتون

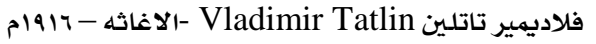

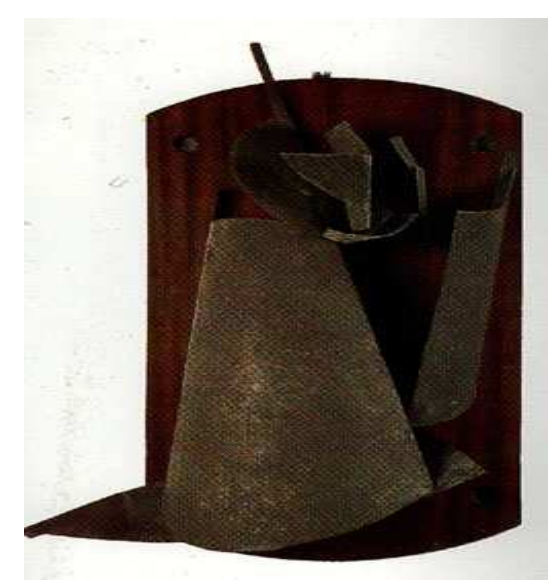

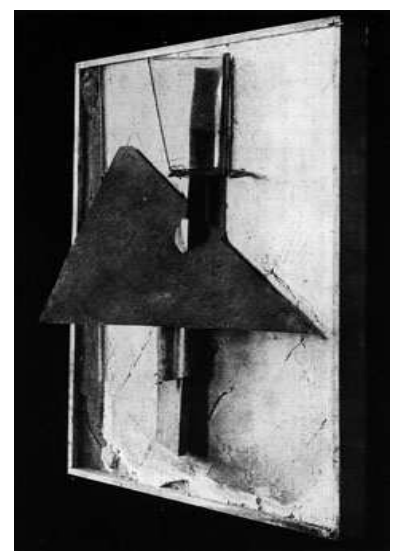

شكل (3)

خشب ومعدن

فلاديمير تاتلين Vladimir Tatlin - نحت بارن

rـ الشكل والمضمون وارتباطه بوسائل التشكيل:-

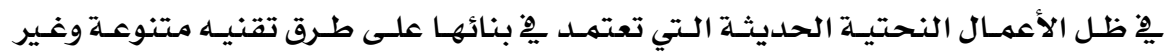

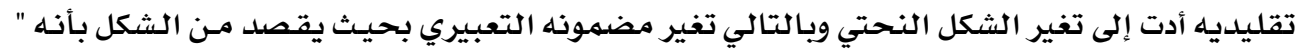

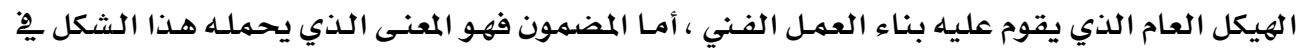

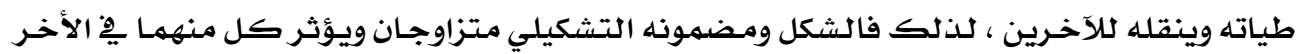

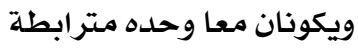

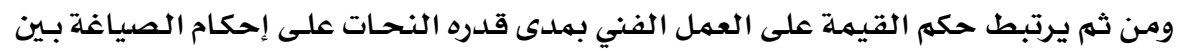

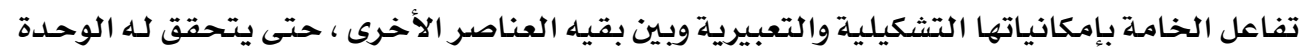

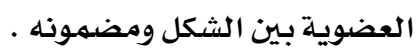

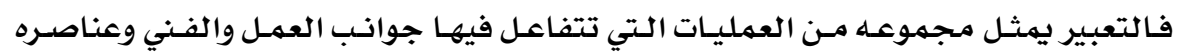

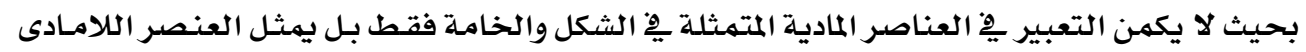

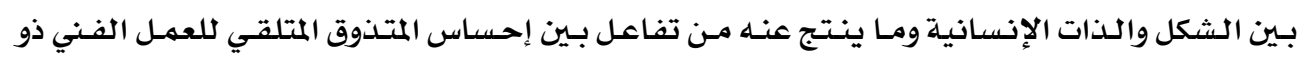


الخبرة والتجـارب الادراكيـة التي تجعلـه يــرك ويتجـاوب مـع العهـل الفـني ومـا يحملـه مـن مـضامـين ومفاهيه تعبيريه .

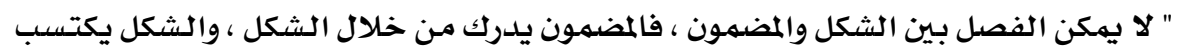

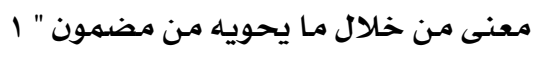

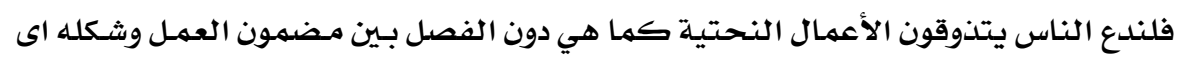

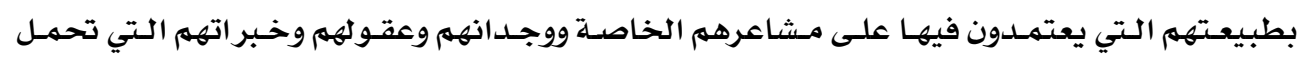

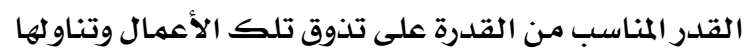

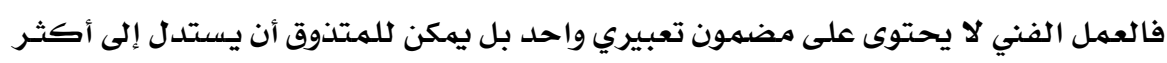

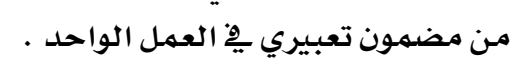

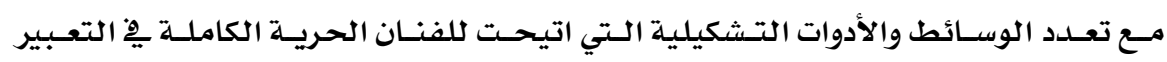

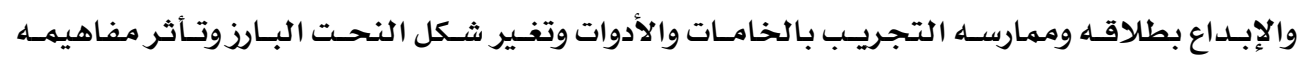

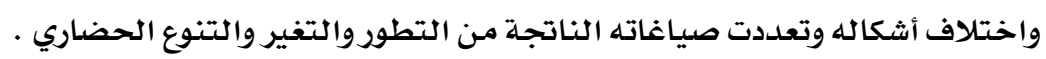

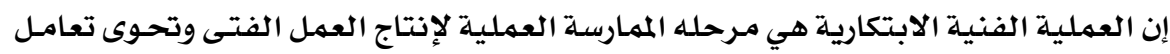

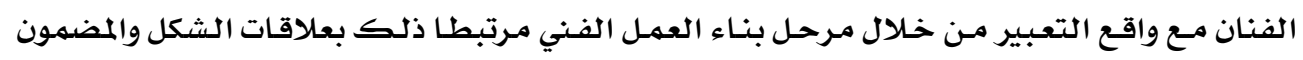

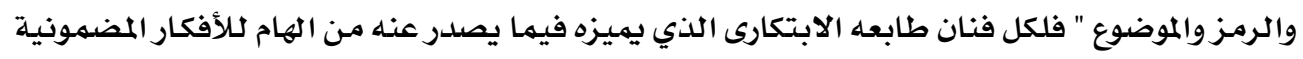

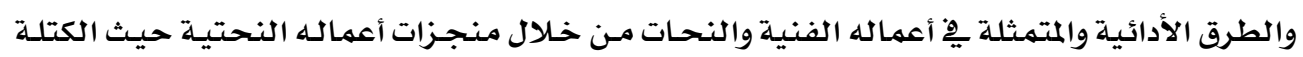

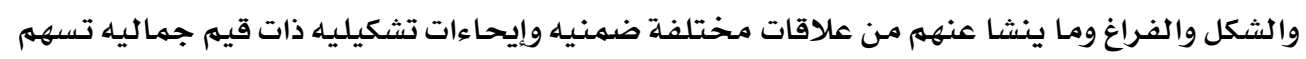

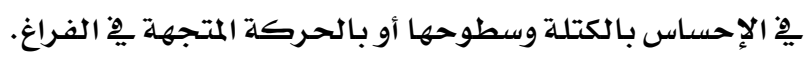

فالطريقة أو الوسيلة هي عملية مركبة بالنسبـة للنحات فمنـذ بـدأ اختيـاره للخامـة والقيـام

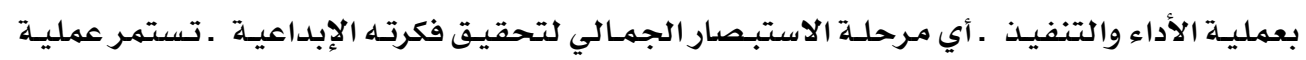

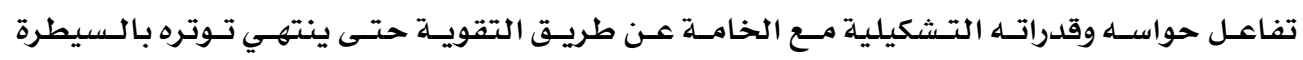
التشكيلية عليها وتجاوبها مـع فكرته التخيلية.

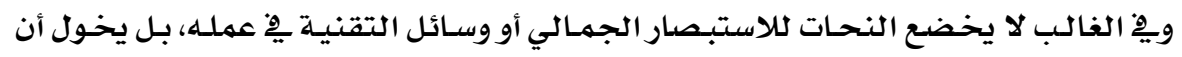

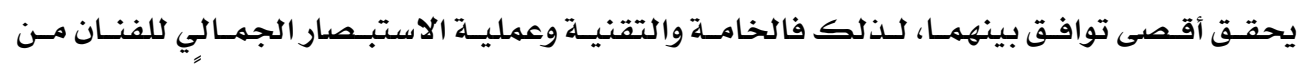

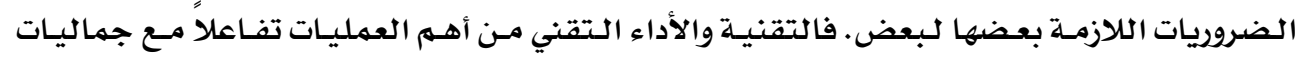

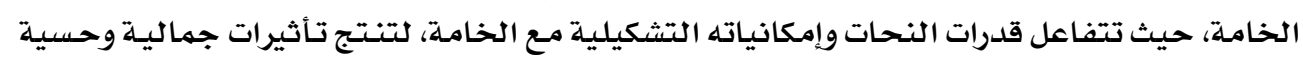

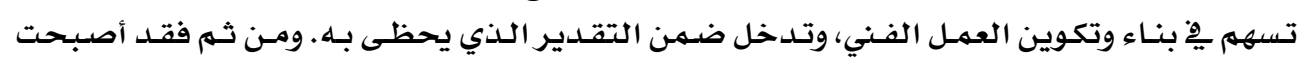

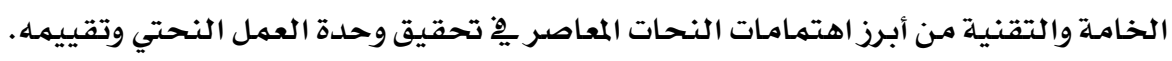

سعيد الوتيرى ، سلوى غريب : أسس التصميـمودورها في تطوير قدرات المصميم ألابتكارييه ،ج ، ، مطابع جامعه حلوان 
ا- امجـد صـلاح الــين التهـامى :" القـيه التشكيليه والتعبيريـه لمحوتـات عنـصـر الحيـوان فى اتجاهـات الفـن

$$
\text { الحديث" - رساله ماجستير - تربيه فنيه - جامعـه حلوان - } 1999 .
$$

2-Robert Myron, Abner sundell:" Modern Art in American" , Cromwell collier , N.Y-.

ب- ارنست فيشر :" ضروره الفن "، ترجمه اسعد حليه ، الهيئه المصريـه العامـه للكتاب ، مصر ، 1991.

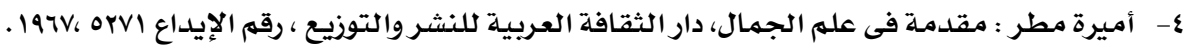
0 - مسن محمد حسن : الاسس التاريخيه للفن التشكيلى المعاصر ، دار الفكر العربى ، الجزء الثانى ،

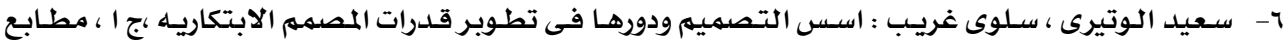
حامعهد حلوان ، القاهره ، 1911 .

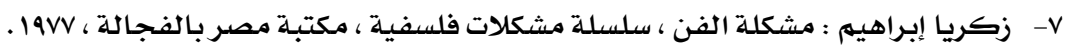

1- عبد الفتاح الديدى : فلسفة الجمال ونشأة الفنون الجميلة ،الهيئة المصرية العامـة للكتب ، مصر ، 1910 . 9- على محمد المليجى : " الابتكاريـ ودافعيه التعبير الفنى للفنان التشكيلى " ، حوليـه كليـه التربيـه جامعـه

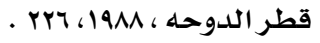

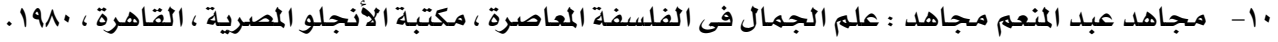
11 - محسن عطية : تذوق الفن ـ دار المعارف ـ مصر. 1990.

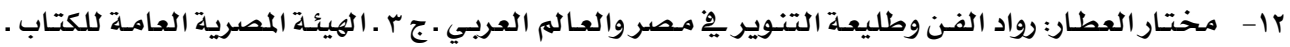
مصر.

سا - محمد اسحق قطب :" المفهوم الجمالى لتناول الخامـه فى النحت الحديث "- رساله دكتوراه - القـاهره -

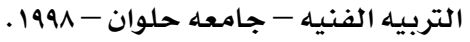

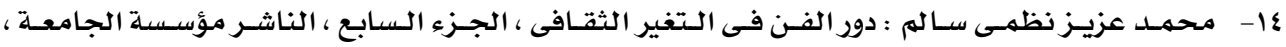

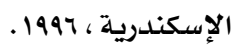

10 - محمد عزيز نظمى : القيم الجمالية ، دار المعارف ، القاهرة ، ع19 19 .

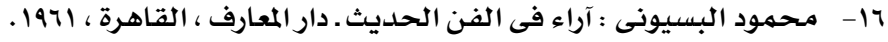

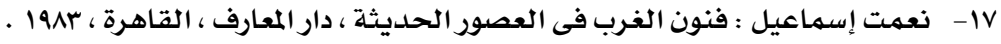

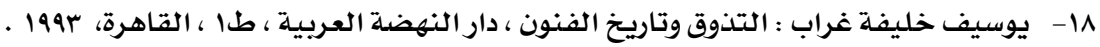

19-Edward Lucie Smith : " Movement in art since 1947 - 1975 " , Thames \& Hudson, London, 1975.

19-H. Read: "Aconcise History Of Modern Sculpture", Thomas \& Hudson, London, 1964.

20-Jack Bernhard: "Beyond Modern Sculpture", George Braziller, New York, 1986. 
21-John, Golding: " Cubism A History And Analysis ", 1907- 1914, Faber \&Faber, London, 1959.

22-L. R. Rogers : "Sculpture The Appreciation Of Art ", Part 2, Oxford , N. Y, 1969.

23-Rosemary Lambert :"The Twentieth Century ,Cambridge , Introduction , To History Of Art" , Cambridge, London, 1981 . 